\title{
Effects of the excessive use of electronic screens on vision and emotional state
}

\author{
Efeitos do uso excessivo de telas eletrônicas na visão e no estado emocional \\ Viviane Fernanda da Silva Barros ${ }^{1}$ (1), Raissa Adriana da Silva Gomes de Oliveira ${ }^{1}$ (1), Robson Borges Maia ${ }^{1}$ (I), \\ Nilma Fernandes ${ }^{2}$ (D) Edna Motta Almodin² (1)
}

Electronic devices: Vision: Ocular health

Descritores:

Telas eletrônicas; Visão; Saúde ocular

Received on: May 11, 2021

Accepted on: Jul 7, 2021

Corresponding author: Edna Motta Almodin Rua Silva Jardim, 359 - Zona 1 Zip code: 87013-010 - Maringá, PR, Brazil E-mail: ealmodin@gmail.com

Institution: Hospital Almodin, Provisão Hospital de Olhos de Maringá, Maringá, PR, Brazil.

Conflict of interest: The authors have no conflicts of interest to declare.

Financial support: no financial support for this work.

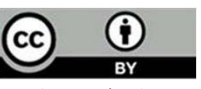

Copyright (C2021

\section{ABSTRACT}

Objective: To investigate relations between electronic screen use and eye health in a representative sample of the Brazilian population.

Methods: Data were collected online and analyzed at a private Brazilian hospital (Provisão Hospital, Maringá, Brazil). Male and female individuals aged 12 to 35 years participated in the study. A populationbased cross-sectional survey based on a questionnaire developed using the Google Forms interface was carried out. The questionnaire was answered anonymously in order to ensure the confidentiality of data and the privacy of participants. Data were collected between October 13, 2020, and January 30 , 2021.

Results: A total of 200 questionnaires were completed. Most responders were young people aged 18 to 27 years. Daily electronic device use time reported by responders ranged from more than 5 hours $(150 ; 75.5 \%)$ to 3 to 5 hours/day $(28 ; 14 \%)$ or 2 to 3 hours/day $(16 ; 8 \%)$. Only a small proportion of responders (2.5\%) used these devices less than 1 hour per day. Most participants had myopia (164; $84 \%)$ and/or astigmatism (151; 75.5\%), whereas keratoconus was less prevalent (34; 17\%). However, 92 participants were unable to say whether they had these diseases or not. Most participants reported eye symptoms after screen use (red eyes, fatigue, dry and gritty eyes and blurred vision). Mental issues such as smartphone dependence and difficulties to communicate while using electronic devices were also addressed. Most responders reported dependence and communication problems.

Conclusions: Most young people in this sample had sings of eye disease, including keratoconus. Smartphone dependence and addition was also observed. Findings presented may inform future studies and help health authorities to properly guide public health strategies aimed at eye disease prevention.

\section{RESUMO}

Objetivo: Investigar o uso de telas na saúde ocular em uma amostra populacional brasileira.

Métodos: Os dados foram adquiridos on-line, e as análises foram realizadas em uma clínica privada na Região Sul do Brasil. Os participantes foram indivíduos de 12 a 35 anos, de ambos os sexos. Foi realizada pesquisa transversal de base populacional por meio de questionário elaborado na plataforma Google Forms. O questionário foi respondido de forma anônima, mantendo o sigilo dos dados coletados e a privacidade dos participantes. A coleta de dados teve início em 13 de outubro de 2020 e término em 30 de janeiro de 2021

Resultados: Foram respondidos 200 questionários. A maioria foi de jovens entre 18 e 27 anos. $O$ tempo de uso de dispositivos eletrônicos durante o dia foi de mais de 5 horas para 150 (75,5\%) entrevistados, 28 (14\%) gastavam de 3 a 5 horas por dia, 16 (8\%) de 2 a 3 horas por dia e uma pequena parte dos entrevistados (2,5\%) usava menos de 1 hora por dia. A maioria dos participantes tinha miopia $(164 ; 84 \%)$ e/ou astigmatismo (151; 75,5\%). Ceratocone foi menos prevalente (34; 17\%), entretanto 92 pessoas não sabiam a resposta. A maioria dos participantes teve problemas nos olhos após o uso da tela, como olhos vermelhos, cansados e secos, além de visão turva. Questões mentais, como dependência de smartphones e dificuldade de comunicação durante o uso do dispositivo, também foram abordadas. A maioria dos entrevistados demonstrou dependência e problemas de comunicação.

Conclusões: A maior parte dos jovens apresentou quadro de doenças oculares, incluindo ceratocone. Dependência e adição de smartphone também foram observados. Esses resultados apoiam a identificação de fatores associados à patologia ocular, servindo de base para estudos futuros, e podem auxiliar às autoridades de saúde no direcionamento adequado das atividades de prevenção e controle em saúde pública. 


\section{INTRODUCTION}

The use of electronic devices has grown in recent years. We live in a society in which electronic devices are becoming an increasingly indispensable part of everyday life. A survey carried out by Getúlio Vargas Foundation, São Paulo (FGV-SP) in 2018 revealed an average of two electronic devices per capita in Brazil, the most popular being the mobile phone..$^{(1)}$

Evidence indicates that unhealthy eating habits, obesity, physical inactivity, violent behavior, smoking, alcohol abuse, depression, sleep disorders, hyperactivity and social and sexual behavior problems may be related to age of media use onset and time spent on digital media. Messages exchanged via these media channels may also affect human behavior. Although social and digital media are not the only causes of such behaviors, they certainly are a significant contributing factor. ${ }^{(2,3)}$

According to some pediatricians, excessive time spent in front of television and computer screens may lead to sleep disorders, which are associated with poor school performance, eye fatigue and mental and physical exhaustion. Over time, these may progress to other problems, such as attention, concentration and memory deficits, depression, headache, and dizziness. ${ }^{(4,5)}$

Data provided by the Annie mobile application revealed that Brazil occupies the 5th position in the global screen time ranking, with higher prevalence of excessive screen time among children and adolescents. National and international studies have shown a significant increase in screen time (i.e., time spent in front of television, computer, tablet, mobile phone and interactive media screens) among children and adolescents in recent years. ${ }^{(6,7)}$ Excessive use of electronic devices can cause several ocular symptoms, such as dry and irritated eyes, itching and blurred vision, among other eye disorders. ${ }^{(4)}$

Up until a few years ago, parents were only concerned with the time their children spent in front of the television. However, these days children use electronic devices on several occasions, including leisure. These devices have become part of our lives. Changes in screen usage patterns may compromise vision in adults as well as in children, whose eyesight is being developed. When near vision is overused, accommodation fatigue ensues and several vision problems may occur. ${ }^{(8)}$

According to Harvard Medical School, excessive exposure to screen light can suppress melatonin secretion, leading to decreased growth hormone (GH) release, circadian rhythm changes and ultimately to sleep disorders and depression. Light emitted by electronic device screens suppresses the release of melatonin by the pineal gland. Therefore, when devices are used at night, the nervous system remains awake in response to light exposure and sleep is impaired, with increased risk of insomnia. In order to sleep well at night, the circadian rhythm must be respected so that the brain can distinguish between day and night according to light change patterns. Hence, the use electronic devices before bed is not recommended. ${ }^{(9)}$

Long hours spent in front of electronic screens without taking a break makes the eyes very dry. While using electronic screens, we tend blink less. For this reason, dry eye syndrome and other vision problems are becoming increasingly common. Ideally, we should blink 15 to 20 times per minute in order to achieve appropriate eye lubrication. However, when the eyes are fixed on screens, blink rate drops to three to five times per minute and dry eyes result. ${ }^{(8)}$

Computer vision syndrome has negative impacts on vision and has become a significant concern. This syndrome is characterized by a range of eye- and vision-related symptoms and has been attracting medical attention for the past 20 years. The terms visual fatigue and digital eye fatigue are also used to describe the condition. Computer vision syndrome is no longer limited to people with long work-related screen exposure. Rather, it has become a public health problem which also affects children and adolescents. ${ }^{(4)}$

The significance of computer vision syndrome and the lack of data on digital device usage patterns in the Brazilian population were the primary motivations for this study. The following research question was addressed: What are the impacts of excessive electronic screen use on individual vision and emotional states? Data collected using an online cross-sectional survey provided an overview of screen usage patterns among Brazilian people and insights into impacts on eye health.

This study was aimed at investigating the impact of electronic screen use on eye health in a representative sample of the Brazilian population.

\section{METHODS}

\section{Study design}

A population-based cross-sectional survey was applied to gather information on screen time and eye health. Data were self-reported via a standardized online questionnaire aimed at identifying major negative impacts 
of excessive use of electronic devices on eye health and daily user performance. This cohort study was used to examine causal relations based on data extracted from a subset of subjects that is representative of the target population.

\section{Patients and analysis}

This research was approved by the Human Research Ethics Committee of University Center Unicesumar (protocol number 4.317.192). Prior to completing the questionnaire, participants read and signed a Free and Informed Consent Form. Male and female individuals aged 12 to 35 years were eligible to participate. Data collection was carried out using a questionnaire developed using Google Forms interface and a survey link disseminated via social media. Questions followed the Likert Scale model.(10) Target age group selection was based on growing rates of electronic screen use in Brazil and mounting prevalence of eye diseases in this age range according to data complied by ophthalmology services. In order to ensure the confidentiality of data collected and the privacy of participants, the questionnaire was answered anonymously. Data were collected between October 13, 2020 and January 30, 2021.

\section{Data analysis}

Descriptive statistics (frequency distribution) were used. Graphs were generated using GraphPad Prism 8.0 software.

\section{RESULTS}

\section{Participant profile}

The number of questionnaires completed totaled 200. The sample comprised 139 (69.5\%) female participants. Participants in this study were aged 12 to 35 years. However, most responders were aged 18 and 27 years. Age stratification was as follows: 11 (5.5\%) responders aged 12 to 17 years, 67 (33.5\%) responders aged 18 to 22 years, 69 $(34.5 \%)$ responders aged 23 to 27 years and $53(26.5 \%)$ responders aged 28 to 35 years.

Daily use of electronic devices reported revealed that $150(75.5 \%)$ responders used their devices for more than 5 hours/day, 28 (14\%) for 3 to 5 hours/day, 16 (8\%) from 2 to 3 hours/day and only a small proportion (2.5\%) less than 1 hour/day (Figure 1).

\section{Eye health}

Aside from assessing individual behavior, questions in this survey were also aimed at investigating eye health.

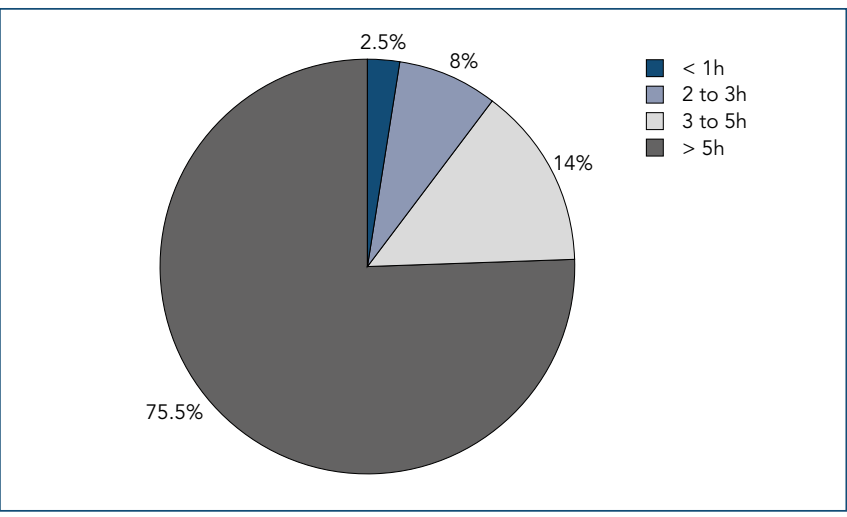

Figure 1. Frequency distribution of daily screen time.

In this sample, $164(84 \%)$ responders reported myopia and $30(15 \%)$ did not. Interestingly, two respondents (1\%) did not know how to answer, suggesting part of the population has no awareness of eye health. The next question was addressed to responders who reported myopia. One hundred and eighty four individuals answered the survey. This proportion was higher than the $84 \%$ that answered yes. This difference may have been due to errors while filling out online forms. This bias was mitigated by the high number of participants. Out of 184 responders, 117 (63.6\%) reported increasing glass strength, 64 (34.8\%) declared their eye condition had stabilized and 2.9 (1.6\%) were unable to say whether their glass strength was increasing or not. Astigmatism was also investigated. One hundred and fifty-one (75.5\%) participants reported astigmatism, 47 $(23.5 \%)$ did not and two (1\%) did not know how to answer.

The prevalence of keratoconus in the target population was 17\% (34 participants). However, a large part (92; 46\%) were unable to tell whether they had this eye disease or not. Therefore, the prevalence of keratoconus in this sample may not have been accurately determined. Occurrence of this eye disease in family members was also investigated. Family history of keratoconus was reported by 31 (15.5\%) of responders, 99 (49.5\%) were unable to inform and 70 (35\%) did not report keratoconus in the family.

When asked to list words that spring to mind when talking about keratoconus, the following terms were reported: fear, vision, illness, blindness, scary, strange, concern, illness, and cone.

As to eye care-related questions, the vast majority of participants (197) reported having been submitted to eye examination at some point in their lives, whereas a small portion had never had access to eye care. Even though ophthalmic consultation was often reported, only 76 (38\%) participants had been submitted to more complex procedures, such as tomography or corneal topography assessment. 


\section{Screen time and eye symptoms}

The following eye symptoms were reported after using screens: fatigue, dry eyes, gritty sensation or itching, redness and insomnia. Only ten (5\%) participants failed to report eye fatigue by the end of the day (Figure 2), whereas the vast majority $(129 ; 64.5 \%)$ reported frequent or very frequent eye fatigue.

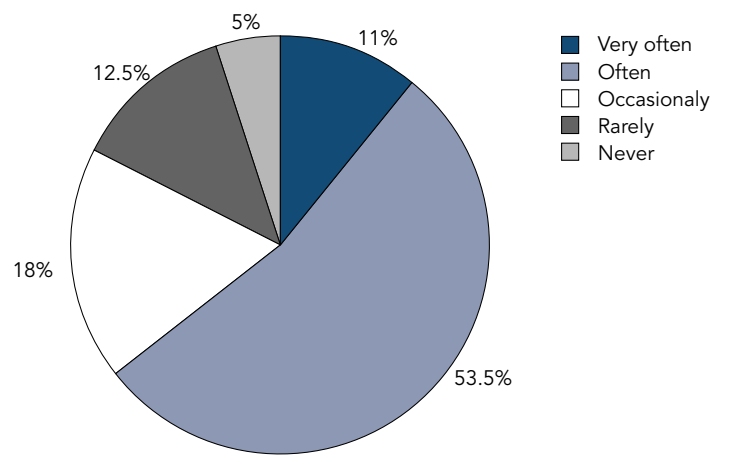

Figure 2. Frequency of eye fatigue by the end of the day reported by participants who answered the questions

As to blurred vision after using electronic devices, seven (3.5\%) respondents described this symptom as very common, 38 (19\%) experienced it often, 74 (36.5\%) occasionally, $61(30.5 \%)$ rarely and $20(10.5 \%)$ had never experienced blurred vision (Figure 3 ).

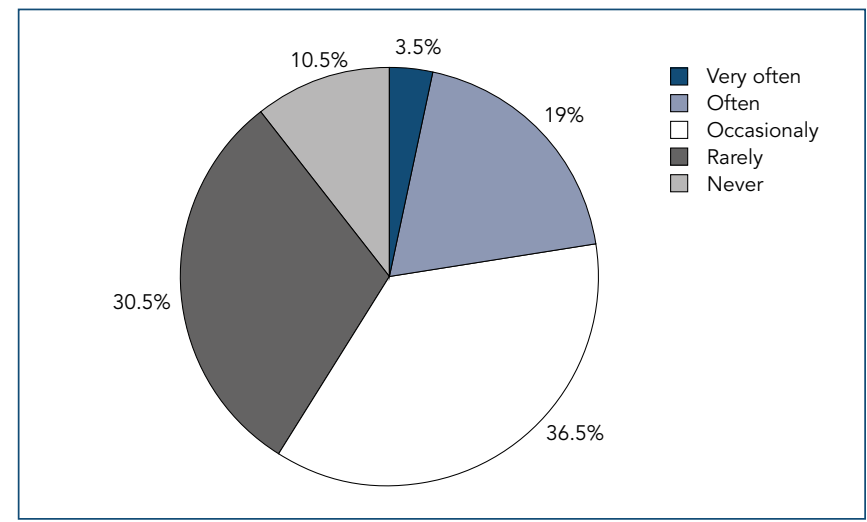

Figure 3. Frequency of blurred vision reported by participants

As to the frequency of insomnia, six (3\%) respondents reported experiencing insomnia very often, whereas 32 (16\%) had insomnia frequently, 65 (32.5\%) occasionally, 58 (29\%) rarely and 39 (19.5\%) never had insomnia.

Gritty eye sensation was reported by most participants $(135 ; 67.5 \%)$. Overall, 21 (10.5\%) respondents reported experiencing gritty eye sensation and itching very often, 114 (57\%) frequently, 19 (9.5\%) occasionally, 27 (13.5\%) rarely and 19 (9.5\%) never (Figure 4).

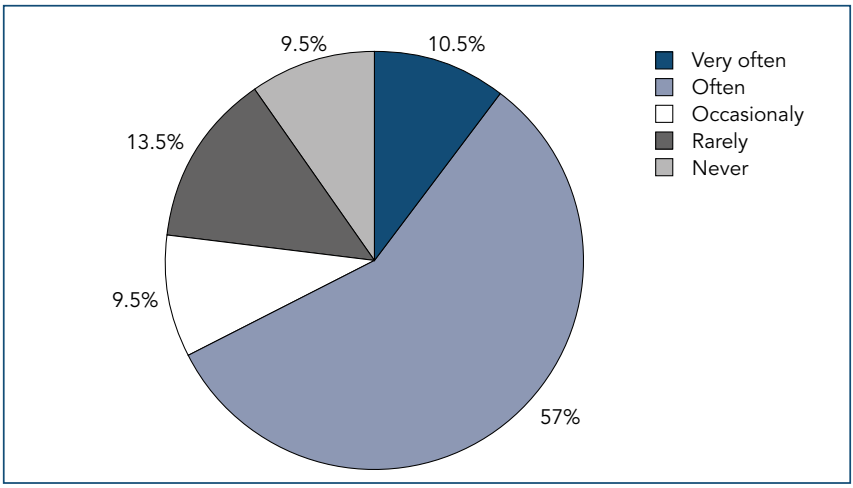

Figure 4. Frequency of gritty eye sensation and itching after screen exposure.

Dry eye frequency was also investigated. Twenty-five $(12.5 \%)$ responders reported experiencing this eye symptom very often, 115 (57.5\%) frequently, 17 (8.5\%) occasionally, $22(11 \%)$ rarely and $21(10.5 \%)$ never. Therefore, the vast majority $(70 \%)$ felt their eyes were dry after screen exposure (Figure 5).

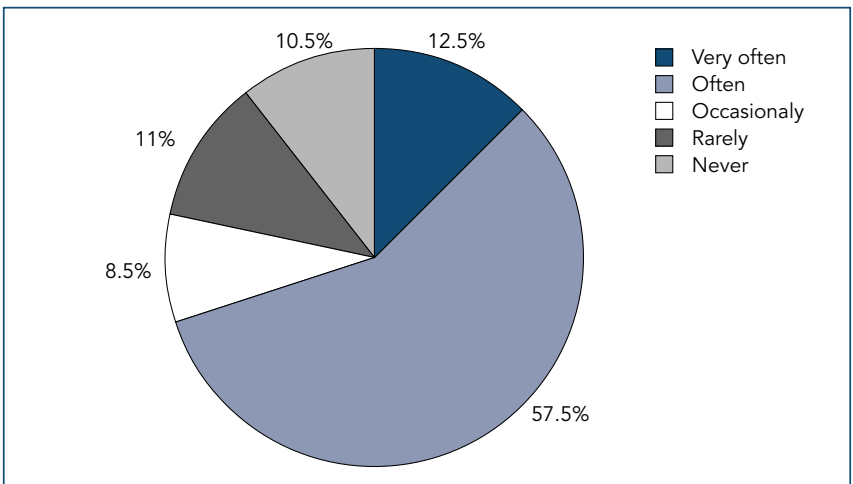

Figure 5. Frequency of dry eyes reported by participants who responded to the survey.

Red eye was another common symptom in this sample (Figure 6). This symptom was reported as very frequent by 22 (11\%) responders, frequent by 108 (54\%), occasional by $22(11 \%)$ and rare by 29 (14.5\%), whereas 19 (9.5\%) reported never having experienced red eyes.

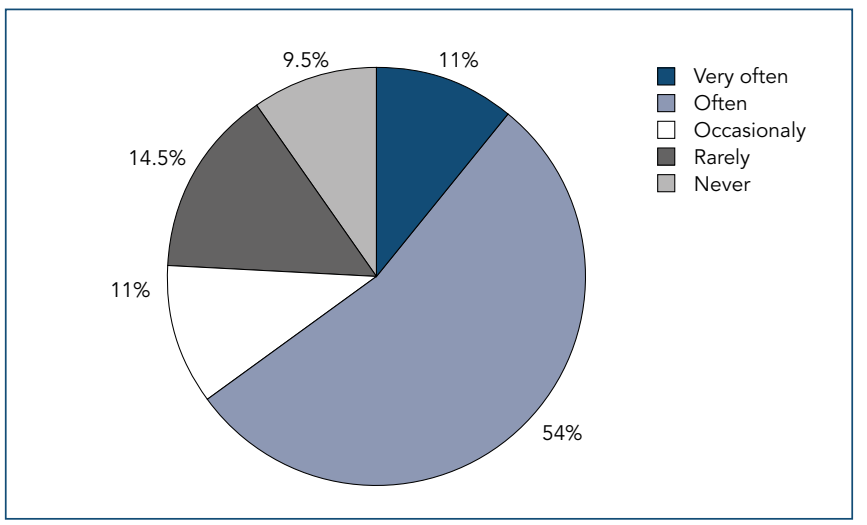

Figure 6. Frequency of red eyes reported by participants who responded to the survey. 


\section{The use of screens and mental health}

Relations between screen time and mental health were also investigated. Participants were asked whether they were unable to communicate verbally or physically with other people while not using a smartphone. Ninety-one participants (45.5\%) agreed with the statement, 102 (51\%) partially agreed, and only 7 (3.5\%) participants disagreed.

As to self-esteem, 59 (29.5\%) of responders declared their self-esteem was high, 115 (57.5\%) average, 21 (10.5\%) moderate and five (2.5\%) low.

As to the feeling of depression, 11 (5.5\%) reported experiencing this symptom frequently, 63 (31.5\%) occasionally, 67 (33.5\%) rarely and 59 (29.5\%) never.

In order to assess excessive dependence on electronic screens, use of smartphones was specifically investigated. When asked how they would feel without a smartphone, many responders declared they could not imagine not having access to these devices for a certain amount of time. This reveals how smartphone-dependent people have become. When asked to describe how they would feel if they had to spend a day with no access to a smartphone, the following words were listed: anxiety, lost, alone, disconnected, a sensation of missing out on something, disoriented, bored, stressed, deprived of information.

\section{DISCUSSION}

Descriptive epidemiology is aimed at identifying patterns of disease distribution in a given population within a set period of time, excluding interventions. Based on these observations, hypotheses can be formulated as to the causes of such patterns and factors that may increase the risk of disease. In other words, descriptive epidemiology can be used to formulate hypotheses. Crosssectional studies may also inform future research into the causes of several diseases. In observational epidemiological studies, data is often self-reported and collected using standardized questionnaires applied in person, over the phone or online. ${ }^{(11)}$ In this study, an online questionnaire (Google Forms) was used, and participants were asked to answer yes/no questions using a Likert scale (e.g., very often, often, rare). Therefore, it was possible to describe a behavioral profile potentially related to eye diseases such as myopia and keratoconus. Findings revealed that young people spent too much time online ( $>5$ hours per day). The frequency of mobile phone use in the target population was surprisingly high and may explain the high prevalence of myopia and astigmatism in this sample (184 and 151 participants; 84\% and 75.5\%, respectively).
It has been suggested that excessive use of computers and mobile phones increases the chances of myopia development. A cross-sectional study with children aged 6 to 18 years revealed positive associations between impaired vision and excessive TV watching. ${ }^{(12)}$ In another study, spending more than 3 hours per day online was thought to be a risk factor for refractive error in children aged 7 to 15 years. ${ }^{13)}$ These studies confirm that the indiscriminate use of electronic screens can lead to an increase in myopia and other ocular pathologies. As to astigmatism, it has recently been shown that rates increase according to years of and average daily exposure to screens. Authors of that study ${ }^{(14)}$ suggested that babies and children who were exposed to screens during childhood may be more prone to astigmatism. In Brazil, high prevalence of excessive screen time has been demonstrated among teenagers, suggesting the need of interventions aimed at changing adolescent behavior. ${ }^{(15,16)}$

Another undesirable consequence of prolonged use of electronic devices is sedentary behavior, which has negative impacts on health, especially in children. ${ }^{(17)}$ As emphasized by the World Health Organization (WHO), limited time for outdoor activities and lack of sun exposure and vitamins are harmful for child development ${ }^{(18)}$ and may account for the increase in eye problems, such as keratoconus in children.

A European study reported that $68 \%$ of children under the age of 3 use a computer regularly. ${ }^{(6)}$ The harmful effects of using screens so early in life are being investigated. However, lacrimal dysfunction syndrome, or dry eye, may certainly result, among other symptoms. Indeed, long daily exposure to TV, smartphone and tablet screens is a known risk factor for dry eye in children. The fact that most participants in this sample $(140 ; 70 \%)$ experienced dry eye frequently or occasionally supports scientific literature data.

Eye fatigue, eye redness and gritty eye sensation were also investigated. Just as in the case of dry eyes, most participants experienced these symptoms often. Eye fatigue and dry eye increase the need to rub the eyes. ${ }^{(19)}$ Chronic friction resulting from repeated rubbing is associated with keratoconus development, a progressive non-inflammatory disorder that leads to thinning of the corneal stroma, astigmatism, myopia and corneal protrusion. ${ }^{(20)}$ Originally a rare disease affecting fewer than 1 in 2,000 people according to the National Institute of Health, findings of the latest literature review suggest the disease may be more prevalent. In the United States, 54.5 in 100,000 people are estimated to be affect. In a recent meta-analysis with more than 7 million patients from 15 different 
countries, an overall prevalence of 138 in 100,000 individuals was calculated. ${ }^{(21,22)}$ The prevalence of keratoconus has risen considerably due to new habits. Despite the lack of official data, experts believe that one in 250 people is affected in Brazil. ${ }^{(23)}$

The world is constantly evolving and modernity is stronger than ever. Hence the use of electronic devices in most households worldwide. Excessive use of these devices, especially by young people, is a growing cause of health problems, including emotional disorders. Findings of this study revealed that participants could not imagine been without a smartphone and felt anxiety and loneliness, among other emotions, when offline. Most respondents also agreed that use of digital devices affects interaction and communication and is becoming a social problem. In fact, evidence suggests the use of smartphones and social media contributes to mental suffering, self-injurious behavior, and suicide among young people. ${ }^{(24)}$

Whether at work or for fun, we find ourselves staring at screens for most of the day. Blue light radiation may severely affect vision. The fact that most people are not aware of this problem may lead to increasing rates of severe eye problems now and in the future. Brazilian eye disease incidence and prevalence data clearly show that the lack of information and studies addressing the dynamics of such ocular pathologies contribute to delayed treatment and hinder prevention. It is estimated that age-related vision problems will increase globally. ${ }^{(25,26)}$ The scarcity of studies investigating screen use in children and adolescents makes it difficult to identify vision problem trends in this age group.

\section{CONCLUSION}

Most young people in this sample reported sings of eye diseases, including keratoconus. Smartphone dependence and addition were emphasized. Findings of this observational study support the identification of factors associated with ocular pathology and may inform future studies and preventive public health strategies and control activities.

\section{REFERENCES}

1. Felisoni DD, Godoi AS. Cell phone usage and academic performance: An experiment. Comput Educ. 2018;117:175-87.

2. Thomas G, Bennie JA, De Cocker K, Castro O, Biddle SJ. A descriptive epidemiology of screen-based devices by children and adolescents: a scoping review of 130 surveillance studies since 2000. Child Indic Res. 2020;13(3):935-50.

3. Strasburger VC, Jordan AB, Donnerstein E. Children, adolescents, and the media: health effects. Pediatr Clin North Am. 2012;59(3):533-87, vii.

4. Mylona I, Deres ES, Dere GS, Tsinopoulos I, Glynatsis M. The impact of internet and videogaming addiction on adolescent vision: a review of the literature. Front Public Health. 2020;8:63.
5. Dworak M, Schierl T, Bruns T, Strüder HK. Impact of singular excessive computer game and television exposure on sleep patterns and memory performance of school-aged children. Pediatrics. 2007;120(5):978-85.

6. Palaiologou I. Children under five and digital technologies: implications for early years pedagogy. Eur Early Child Educ Res J. 2016;24(1):5-24.

7. Bucksch J, Sigmundova D, Hamrik Z, Troped PJ, Melkevik O, Ahluwalia N, et al. International Trends in Adolescent Screen-Time Behaviors From 2002 to 2010. J Adolesc Health. 2016;58(4):417-25.

8. Moon JH, Kim KW, Moon NJ. Smartphone use is a risk factor for pediatric dry eye disease according to region and age: a case control study. BMC Ophthalmol. 2016;16(1):188.

9. Harvard Health Publishing. Harvard Medical School. Blue light has a dark sid. 2020. [cited $2021 \mathrm{Jul}$ 1]. Available from: http://www.health.harvard. edu/staying-healthy/blue-light-has-a-dark-side

10. Likert R. A technique for the measurement of attitudes. Arch Psychol. 1932;22(140):5-55.

11. Saczynski JS, McManus DD, Goldberg RJ. Commonly used data-collection approaches in clinical research. Am J Med. 2013;126(11):946-50.

12. Bener A, Al-Mahdi HS. Internet use and television viewing in children and its association with vision loss: a major public health problem. J Public Health Africa. 2012;3(1):e16

13. Sewunet SA, Aredo KK, Gedefew M. Uncorrected refractive error and associated factors among primary school children in Debre Markos District, Northwest Ethiopia. BMC Ophthalmol. 2014;14(1):95.

14. Huang L, Yang GY, Schmid KL, Chen JY, Li CG, He GH, et al. Screen exposure during early life and the increased risk of astigmatism among preschool children: Findings from longhua child cohort study. Int J Environ Res Public Health. 2020;17(7):1-13.

15. Schaan CW, Cureau FV, Sbaraini M, Sparrenberger K, Kohl III HW, Schaan BD. Prevalence of excessive screen time and TV viewing among Brazilian adolescents: a systematic review and meta-analysis. J Pediatr (Rio J). 2019;95(2):155-65.

16. Schaan CW, Cureau FV, Bloch KV, de Carvalho KM, Ekelund U, Schaan $\mathrm{BD}$. Prevalence and correlates of screen time among Brazilian adolescents: findings from a country-wide survey. Appl Physiol Nutr Metab. 2018;43(7):684-90.

17. Morgan IG, He M, Rose KA. Epidemic of pathologic myopia: What can laboratory studies and epidemiology tell us? Retina. 2017;37(5):989-97.

18. World Health Organization (WHO). WHO Guidelines on physical activity, sedentary behaviour and sleep. For children under 5 years of age. Geneve: $\mathrm{WHO}$; 2019. Available from: https://apps.who.int/iris/handle/10665/311664

19. Najmi H, Mobarki Y, Mania K, Altowairqi B, Basehi M, Mahfouz MS, et al. The correlation between keratoconus and eye rubbing: A review. Int J Ophthalmol. 2019;12(11):1775-81

20. Alió JL, Vega-Estrada A, Sanz-Díez P, Peña-García P, Durán-García ML, Maldonado M. Keratoconus management guidelines. Int J Keratoconus Ectatic Corneal Dis. 2015;4:1-39.

21. Ferrari G, Rama P. The keratoconus enigma: A review with emphasis on pathogenesis. Ocul Surf. 2020;18(3):363-73.

22. Hashemi H, Heydarian S, Hooshmand E, Saatchi M, Yekta A, Aghamirsalim $M$, et al. The prevalence and risk factors for keratoconus: a systematic review and meta-analysis. Cornea. 2020;39(2):263-70.

23. Ambrósio R. Avanços em ceratocone: quebra de paradigmas, mas com paradoxos. Exame [Internet]. 2018 [citado 2021 Jul 1]. Disponível em: https://exame.abril.com.br/negocios/releases/avancos-em-ceratoconequebra-de-paradigmas-mas-com-paradoxos/

24. Abi-Jaoude E, Naylor KT, Pignatiello A. Smartphones, social media use and youth mental health. Can Med Assoc J. 2020;192(6):E136-41.

25. Flaxman SR, Bourne RR, Resnikoff S, Ackland P, Braithwaite T, Cicinelli MV, et al.; Vision Loss Expert Group of the Global Burden of Disease Study. Global causes of blindness and distance vision impairment 1990-2020: a systematic review and meta-analysis. Lancet Glob Health. 2017;5(12):e1221-e1234.

26. Bourne RRA. Vision 2020: Where are we? Curr Opin Ophthalmol. 2020;31(2):81-4 